\title{
Changes in functional limitations and survival among the elderly in Taiwan: 1993, 1996, and 1999
}

\author{
Zachary Zimmer \\ Population Council \\ Linda G. Martin \\ Population Council \\ Ming-Cheng Chang
}

Follow this and additional works at: https://knowledgecommons.popcouncil.org/departments_sbsr-pgy

Part of the Demography, Population, and Ecology Commons, Family, Life Course, and Society Commons, Gerontology Commons, and the International Public Health Commons How does access to this work benefit you? Let us know!

\section{Recommended Citation}

Zimmer, Zachary, Linda G. Martin, and Ming-Cheng Chang. 2002. "Changes in functional limitations and survival among the elderly in Taiwan: 1993, 1996, and 1999," Policy Research Division Working Paper no. 155. New York: Population Council. 
0

$\mapsto$

$\infty$

$\mapsto$

Changes in Functional

$>$

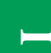

Limitations and Survival

ค

Among the Elderly in Taiwan: 1993, 1996, and 1999

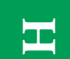

u

Zachary Zimmer

Linda G. Martin

$\approx$

Ming-Cheng Chang

$\varangle$

되

2002 No. 155

$\infty$

[T]

논

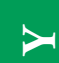

$\cup$

$\mapsto$

$\mapsto$

0

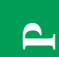

5 Y Y E A R S

P. Population Council 


\title{
Changes in Functional Limitations and Survival Among the Elderly in Taiwan: 1993, 1996, and 1999
}

\author{
Zachary Zimmer \\ Linda G. Martin \\ Ming-Cheng Chang
}

Zachary Zimmer is Research Associate, Population Council, New York. Linda G. Martin is President, Population Council, New York. Ming-Cheng Chang is Deputy Director-General, Bureau of Health Promotion, Taichung, Taiwan. This research is supported by a grant from the National Institute on Aging (No. R01 AG20063-01). 


\begin{abstract}
This paper focuses on changes in the prevalence of functional limitations among nationally representative samples of adults aged 65 and older in Taiwan as measured in 1993, 1996, and 1999. Using data from the Survey of Health and Living Status of the Elderly in Taiwan, we investigate changes in difficulties walking and climbing stairs, two tasks that represent basic lower body movements that are less likely to be influenced by changes in living environments and social roles than are activities of daily living and instrumental activities of daily living. Results are shown for both unadjusted prevalence rates and rates adjusted for changes in population composition. Findings indicate that Taiwan does not appear to be experiencing the improvements in functioning that have been witnessed recently in the United States. The prevalence of functional limitation increased between 1993 and 1996 and between 1996 and 1999. One possible reason for the increase in limitation is the change in old-age survival in Taiwan, which appeared over the study period to have benefited those who have functional limitations, especially in a severe form. The country's Universal Health Insurance program, established in 1995, may have increased access to care and thus survival of those in poorest health.
\end{abstract}

This material may not be reproduced without written permission from the authors. 
Demographers and social gerontologists have long recognized that population aging, a growth in the number and proportion of older persons within a population, is occurring in many parts of the world and creates a number of challenges. Older adults, for instance, are more likely to use health services and to require assistance conducting everyday tasks than are younger people. Accordingly, determining the prevalence of functional limitation among the elderly is essential for forecasting the long-term needs of populations characterized by aging.

Nowhere in the world is the pace of aging more rapid than in some populations in Asia (United Nations 2001). A number of Asian populations are experiencing transformations from young to old age structures, and these countries will subsequently be faced with a multitude of health care and other policy challenges (Hermalin 1995). Taiwan is a typical example of such a population. The proportion of those aged 65 and older was about 8 percent in 1999, but this proportion is expected to more than double by the year 2026 as the sharp declines in fertility and increases in survival that were experienced in the last half of the twentieth century transform the age structure (DGBAS 2000; Ministry of the Interior 2000). Moreover, the large families in Taiwan today, which provide older adults with a number of children to rely upon for their support needs, will soon be replaced by much smaller families.

The growing number and proportion of older adults point to the need to understand the level of and trends in health beyond the basic measure of mortality. In this study we employ a longitudinal data set that yields a time series of cross-sections to determine how functional status among older Taiwanese changed during the 1990s, a period of considerable socioeconomic development in Taiwan. While few such studies have been conducted in non-Western populations, the topic has been actively investigated in the United States, in particular, in recent decades. Evidence from the 1970s and early 1980s indicates that gains in life expectancy in the U.S. were accompanied by increases in the prevalence of functional difficulties (Colvez and Blanchet 1981), suggesting a tradeoff between longer lives and worsening health (Verbrugge 1984). Using a multistate life table approach, Crimmins, Hayward, and Saito (1994) provided simulations for the mid-1980s of how functioning could worsen even as mortality declined and speculated that such a pattern might be expected in the initial stages of declines in death 
rates associated with chronic diseases. Waidmann, Bound, and Schoenbaum (1995) suggested that reports of deteriorating health among older Americans for the 1970s and 1980s may also be a function of earlier diagnosis and improved access to care for preexisting conditions.

More recent evidence for the United States indicates the occurrence of declines in disability and improvements in functioning from the early 1980s to the late 1990s. Manton, Corder, and Stallard (1993, 1997) and Manton and Gu (2001) found declines using data from the National Long Term Care Surveys from 1982 to 1999, as did Freedman and Martin (1998, 1999, 2000) using the 1984 and 1993 Survey of Income and Program Participation and the 1984 and 1994 Supplements on Aging to the National Health Interview Survey. Crimmins, Saito, and Reynolds (1997) found improvements from 1982 to 1993 using data from the National Health Interview Survey, but no change and possibly some deterioration from 1984 to 1990 using the Longitudinal Survey on Aging. These studies and others are well summarized in Schoeni, Freedman, and Wallace (2001). Of course, the studies differ in many respects beyond the data sets used and the time periods covered. There are variations in the age groups studied (e.g., 50+, 65+, $70+, 76+$ ) and in the reference period (current difficulty versus chronic difficulty). Moreover, there are important differences in the measures of health that are used. For example, Freedman and Martin $(1998,1999,2000)$ use the so-called Nagi items that reflect the inability to conduct upper and lower body movements, such as lifting and climbing. Manton and colleagues and many of the other studies use the assortment of activities of daily living (ADLs), such as ability to bathe or use the toilet, and instrumental activities of daily living (IADLs), such as ability to shop or manage money. These measures are influenced by living environments and social role expectations; and according to the studies that use them, generally only difficulty with IADLs appears to be declining (Schoeni, Freedman, and Wallace 2001).

Our investigation assesses whether or not older adults living in Taiwan have experienced similar improvements in functional status between 1993 and 1999. The focus is on changes in prevalence, that is, population-wide rates of functional limitation. The period 1993 to 1999 was characterized by a number of changes in Taiwan's social and 
economic structure that might influence older adult health. While the proportion of the population that is elderly increased substantially, the country's economic growth and rapidly developing infrastructure may have provided greater opportunities for health care and better access to health-related information. In 1995 Taiwan instituted a Universal Health Insurance program (Taiwan Department of Health 1999) that provided health insurance coverage for the entire population for preventive services and for most inpatient, outpatient, and in-home medical care. The introduction of this plan resulted in a rapid and dramatic increase in use of both outpatient and inpatient care (Chiang 1997). Concurrently, Taiwan experienced an increase in life expectancy (Population Reference Bureau 1990, 2001).

\section{DATA}

Data for this study come from three waves of the Survey of Health and Living Status of the Elderly in Taiwan, a project jointly conducted by the Taiwan Provincial Institute of Family Planning, in Taichung, and the Population Studies Center at the University of Michigan, and funded by the US National Institute on Aging. Here we use data from the second, third, and fourth waves of the study (1993, 1996, and 1999), although respondents aged 60 and older were first interviewed in 1989. The first wave is not used in the current study because of a change in response categories from the first to second wave; response categories remained identical through the next three waves. However, it is worth reviewing the initial sampling procedures used for the first wave since most of the cases in the second through fourth waves were selected from this initial sample. Taiwan maintains a Household Register of each resident, and this register was used to select a random sample. Three stratified sampling stages were employed. First, a number of "townships" or administrative units were selected from the country's 361 administrative units. Second, a selection of "blocks" or lins was made within townships. Third, two eligible individuals within each block were randomly selected to be interviewed. The final sampling ratio was $1 / 370$. (Further information on the sampling procedure and the other methods used in the data collection can be found in Taiwan Provincial Institute of Family Planning 1989.) 
For this study we focus on the population aged 65 and older. In the 1993 survey, this group represents survivors from the first wave of data collection aged 61 and older in 1989. In 1996 these individuals were aged 68 and older, and in 1999 they were 71 and older. The 1996 survey included an "aged-in" component of individuals aged 50 to 67 who were interviewed for the first time using a similar questionnaire. The initial 1989 survey consisted of a nationally representative sample. National representation meant both that the noninstitutionalized older population was included in the random selection of respondents and that a special effort was made to include institutionalized individuals and, through the use of proxy respondents, individuals who were incapable of answering the questions. If attrition were random, this strategy, plus the aged-in component, would allow for nationally representative cross-sectional samples of Taiwanese aged 65 and older in the years 1993, 1996, and 1999. However, the randomness of those refusing a follow-up interview cannot be assured. Because of matching to death records, we know who is a decedent and who is a dropout, and we do not believe that dropouts greatly hamper our analysis for several reasons. First, we have examined the dropouts across functional characteristics and have determined that they do not appear to differ substantially from the total population. Second, response rates for these surveys are high ( 89 percent or better). Third, each wave attempted to survey every respondent dating back to the wave of entry into the sample whether or not there was an interim refusal. So, an individual who refused to participate in 1993 does not necessarily represent a dropout from the survey in subsequent waves. Fourth, we follow an imputation procedure used by Crimmins, Saito, and Reynolds (1997) by replacing missing values due to attrition with probabilistic values derived from available observations.

There were 3,852 individuals aged 61 and older interviewed in 1989. Survivors would be 65 and older in 1993 and eligible to be part of the current study; 579 died in the interim, 284 did not respond to the follow-up questionnaire, and 2,989 were reinterviewed in 1993, providing a response rate of 91 percent. Response rates were 89 percent for both the 1996 and 1999 follow-up. The last two surveys included the responding survivors from the 1993 survey plus individuals who were aged-in in 1996. The total responding sample sizes in 1996 and 1999 were 2,963 and 2,890 respectively. 
We conducted all the analyses reported below twice: first treating those who did not respond to follow-up surveys as missing cases, and second by imputing values for missing responses and doing the analyses for all individuals who would have survived the survey period. We compared imputed results with nonimputed results in order to test for sensitivity due to attrition. To impute values, we used the functional states that are observed to determine probabilistically, through maximum likelihood, an estimated value for the year in which a particular observation was missing. The missing observation was then assigned a 0 or 1 response based on the estimated probability. To increase the number of data points available for missing data imputation, we included the 1989 wave for this procedure. The results we obtained from the imputed data were not significantly different from the nonimputed results. In fact, rates of functional limitation vary by less than 1 percent between the imputed and nonimputed data. The results we report in this study are for imputed data; nonimputed results are available from the authors upon request.

The first two survey waves (1989 and 1993) were self-weighted samples, that is, they are nationally representative without weighting. However, in 1996 and 1999 younger ages are underrepresented even when the aged-in component is added, because the agedin sample is smaller in relative terms than the initial sample. It is necessary, therefore, to give greater weight to the aged-in sample than to the original sample. The weights for the later surveys were developed using household registration information. The weighted sample sizes for the 1996 and 1999 waves are a little larger than the unweighted sizes since the aged-in sample is given a higher weight.

\section{METHODS}

\section{Measures of physical functioning}

Each of the three survey waves asked respondents whether they have any difficulty carrying out a number of physical tasks that require upper or lower body movement. These items, which Nagi $(1965,1991)$ termed functional limitations, include tasks such as lifting, climbing stairs, walking a given distance, crouching, grasping small objects, and reaching above the head. For this study, we use only questions that were 
identically worded in the three survey waves: walking 200 to 300 meters and climbing two or three flights of stairs. The question for both items was, "If you have to do the following by yourself, would you have difficulties? If you have difficulties, do you have some difficulty, great difficulty, or are you completely unable to do the task?" No specific reference periods were mentioned in the questions.

We use walking and climbing difficulties in several ways to assess changes in overall functioning. First, we code each individual item as a 1 if the respondent (or the respondent's proxy) reports difficulty with the task and 0 if not. Second, we consider three summary measures of functional limitation that indicate different levels of limitation. The first is whether individuals report at least one of the two limitations; individuals are coded as 1 if they report difficulty with at least one of the tasks and 0 if not. The second is whether individuals report both limitations, also coded 1 if limitations are reported and 0 if not. Finally, we consider whether individuals report that both limitations are severe, that is, done with great difficulty or not at all. Those who report severe difficulty with both tasks are coded 1 , and others are coded 0 .

\section{Estimating prevalence and changes in prevalence}

A prevalence rate for a functional limitation is defined as the number of individuals who report a limitation divided by the total population at a given time. Our main objective is to determine whether prevalence rates for each specific limitation (walking and climbing) and rates for any, both, and both severe limitations changed between the three survey waves. We first examine unadjusted results; then, to account for possible changes in the composition of the population, we consider a number of covariates in multivariate models. These include age (measured in five-year groups), sex (1 for female, 0 for male), marital status ( 1 for married, 0 for other), education (none, no more than primary, and more than primary), and ethnicity ( 1 for Mainlander, 0 for other). Taiwan is ethnically a fairly homogenous population. However, there is a group of individuals who arrived in Taiwan after the civil war in China in the late 1940s; they were mostly male soldiers and were less likely to marry. These individuals, known as Mainlanders, fled the communist regime and followed Chiang Kai-shek to Taiwan. Because 
this group is select, its health-related behaviors and its functional status differ from those of the rest of the elderly population, and it is worth considering them as a separate ethnic group. Because many of them were soldiers, and because they tended to take up jobs that provided them with health insurance throughout their lives, they may be more physically fit and otherwise healthier at older ages than are others. A measure for rural/ urban residence in Taiwan was also considered initially; but Taiwan is a small nation with few rural regions, and our analyses suggested very little difference in functioning between any rural/urban demarcations.

To determine whether or not there were significant changes in prevalence of functional limitations over time, we pool cross-sectional samples for 1993, 1996, and 1999. We fit logistic models for specific difficulties and for our summary measures, which include dummy variables for year of survey, using 1993 as the comparison category, and the compositional variables described above. These regressions take the form of:

$$
\ln (\mathrm{P} / 1-\mathrm{P})=\alpha_{0}+\alpha_{1} \text { Year } 1996+\alpha_{2} \text { Year } 1999+\alpha_{3} \mathrm{x}_{3} \ldots \alpha_{10} \mathrm{x}_{10}
$$

where $\alpha_{3} \mathrm{x}_{3} \ldots \alpha_{10} \mathrm{x}_{10}$ represent eight compositional variables, namely age ( 3 categories with the fourth as a reference), sex (1), marital status (1), education (2), and ethnicity (1). Sex, education, and ethnicity are assumed not to vary over time, and information is taken from the 1993 wave. For age and marital status, appropriate time-varying values from the individual waves are entered.

\section{Changes in survival probabilities}

Our empirical examination concludes with an unadjusted estimation of survival probabilities across categories of functional limitation. This procedure is conducted to help determine whether observed changes in functional limitation can be partially explained by differentials in survivorship in old age. Although there is some attrition across survey waves, the samples are linked to a national register that allows us to determine in all cases whether a loss is due to refusal to be interviewed or to the death of the respondent. This means that the survival analysis is completely free of missing responses due to follow-up. 


\section{Changes in Prevalence}

Table 1 shows unadjusted rates of functional limitation among older adults in Taiwan in 1993, 1996, and 1999. It appears that functional limitations are on the rise in Taiwan, in contrast to recent trends in the United States. The proportion of those 65 and older reporting difficulty climbing increased by almost half, as did the proportion with difficulty walking. The proportion who report one of the two functional problems has risen from about 26 percent in 1993 to about 30 percent in 1996 and further to about 36 percent in 1999. The proportion who report both walking and climbing limitations also increased by about ten percentage points, from 14 to 24 percent, between 1993 and 1999. Similarly, the proportion reporting that they are severely limited in both functions increased from about 8 percent in 1993 to about 13 percent in 1999. All differences are statistically significant based on chi-square tests.

One possible reason for the increase in prevalence across years is the changes in population composition occurring in Taiwan. For instance, with decreasing mortality the older population may be aging, and since age is associated with the probability of reporting functional limitations, the increase in prevalence may be a function of the changing age structure. Table 2 shows how the composition of the Taiwanese elderly population has changed between 1993, 1996, and 1999. The average age of those 65 and older increased by 1.4 years between 1993 and 1999, while the proportion in older age categories increased. For instance, the proportion 80 and older increased from about 12 percent to about 16 percent over the survey years. Although the distribution of the elderly by sex, martial status, and ethnicity has not changed significantly, the Taiwanese

Table 1 Unadjusted prevalence rates for functional limitations across survey years among Taiwanese adults aged 65 and older

\begin{tabular}{lrrrr}
\hline Percent with & $\mathbf{1 9 9 3}$ & $\mathbf{1 9 9 6}$ & $\mathbf{1 9 9 9}$ & P-value \\
\hline Problems climbing & 22.9 & 27.8 & 32.8 & 0.000 \\
Problems walking & 17.0 & 18.8 & 26.9 & 0.000 \\
At least one limitation & 25.5 & 30.1 & 35.7 & 0.000 \\
Both limitations & 14.4 & 16.4 & 24.1 & 0.000 \\
Severe form of both limitations & 7.7 & 9.4 & 12.8 & 0.000 \\
\hline
\end{tabular}


Table 2 Composition of the Taiwanese population aged 65 and older across survey years

\begin{tabular}{llllr}
\hline & $\mathbf{1 9 9 3}$ & $\mathbf{1 9 9 6}$ & $\mathbf{1 9 9 9}$ & P-value \\
\hline Mean age & 71.8 & 72.4 & 73.2 & 0.000 \\
Five-year age cohorts & & & & \\
$\quad 65$ to 69 & $43.1 \%$ & $38.1 \%$ & $33.0 \%$ & 0.000 \\
70 to 74 & 29.2 & 30.9 & 31.0 & \\
75 to 79 & 16.1 & 17.3 & 20.5 & \\
$\quad 80$ and older & 11.6 & 13.7 & 15.5 & \\
Sex & & & & \\
Male & $56.7 \%$ & $56.7 \%$ & $54.6 \%$ & 0.125 \\
Female & 43.3 & 43.3 & 45.4 & \\
Marital status & & & & \\
$\quad$ Married & $60.4 \%$ & $60.6 \%$ & $60.5 \%$ & 0.968 \\
$\quad$ Not married & 39.6 & 39.4 & 39.5 & \\
Ethnicity & & & & \\
$\quad$ Mainlander & $23.1 \%$ & $24.7 \%$ & $22.5 \%$ & 0.105 \\
$\quad$ Other & 76.9 & 75.3 & 77.5 & \\
Education & & & & \\
$\quad$ None & $49.4 \%$ & $44.4 \%$ & $41.3 \%$ & 0.000 \\
$\quad$ Primary & 31.3 & 33.6 & 36.7 & \\
$\quad$ More than primary & 19.4 & 22.0 & 22.0 & \\
Weighted sample size & 2,859 & 3,169 & 3,442 &
\end{tabular}

elderly tended to be more highly educated in 1999 than in 1996 or 1993. For instance, the proportion without any education dropped from about 49 percent to 44 percent to 41 percent, respectively.

The significant age and education changes may be influencing the overall prevalence of functional limitations. Whereas rising average age would tend to increase the proportion with functional difficulties, all else being equal, higher levels of education over time might lower this proportion. Table 3 examines the summary functional limitation measures by age and education to determine whether the overall patterns of prevalence change observed in Table 1 hold across various age and education groups. The table suggests that changes in age and education do not explain the previously observed increase in functional limitation. There is a clear pattern of increasing prevalence of at least one limitation, both limitations, and severe forms of both limitations across survey 
Table 3 Measures of functional limitation, by five-year age cohort and education, across survey years

\begin{tabular}{|c|c|c|c|c|}
\hline & 1993 & 1996 & 1999 & P-value \\
\hline \multicolumn{5}{|c|}{ Percent with at least one limitation } \\
\hline \multicolumn{5}{|l|}{ Age } \\
\hline 65 to 69 & 17.2 & 20.4 & 24.9 & 0.000 \\
\hline 70 to 74 & 23.3 & 27.7 & 30.7 & 0.001 \\
\hline 75 to 79 & 33.8 & 37.2 & 42.1 & 0.015 \\
\hline 80 and older & 49.5 & 53.6 & 60.2 & 0.007 \\
\hline \multicolumn{5}{|l|}{ Education } \\
\hline None & 34.1 & 42.1 & 48.4 & 0.000 \\
\hline Primary & 21.0 & 24.5 & 31.9 & 0.000 \\
\hline More than primary & 10.7 & 14.4 & 17.8 & 0.002 \\
\hline \multicolumn{5}{|c|}{ Percent with both limitations } \\
\hline \multicolumn{5}{|c|}{ Age } \\
\hline 65 to 69 & 8.9 & 10.5 & 15.0 & 0.000 \\
\hline 70 to 74 & 11.3 & 13.6 & 20.1 & 0.000 \\
\hline 75 to 79 & 21.0 & 19.9 & 29.0 & 0.000 \\
\hline 80 and older & 33.8 & 34.9 & 45.3 & 0.000 \\
\hline \multicolumn{5}{|l|}{ Education } \\
\hline None & 19.2 & 24.3 & 33.1 & 0.000 \\
\hline Primary & 12.0 & 12.0 & 21.0 & 0.000 \\
\hline More than primary & 6.0 & 7.5 & 12.3 & 0.000 \\
\hline \multicolumn{5}{|c|}{ Percent with severe form of both limitations } \\
\hline \multicolumn{5}{|l|}{ Age } \\
\hline 65 to 69 & 4.2 & 5.4 & 6.4 & 0.058 \\
\hline 70 to 74 & 5.6 & 7.3 & 9.6 & 0.005 \\
\hline 75 to 79 & 12.8 & 11.3 & 15.0 & 0.148 \\
\hline 80 and older & 18.4 & 23.3 & 30.4 & 0.000 \\
\hline \multicolumn{5}{|l|}{ Education } \\
\hline None & 10.7 & 14.6 & 18.9 & 0.000 \\
\hline Primary & 5.8 & 6.7 & 10.4 & 0.000 \\
\hline More than primary & 3.1 & 3.3 & 5.7 & 0.025 \\
\hline
\end{tabular}

years, with the highest prevalence reported in 1999 for all categories of age and education. All but two of these prevalence differences (aged 65 to 69 and 75 to 79 for the percent with severe forms of both limitations) are statistically significant at a .05 level.

To examine whether or not the changes in prevalence hold when simultaneously adjusting for compositional variables, and to estimate the magnitude of these changes, Table 4 presents results of logistic regression equations for the summary measures of 
functional limitation and for both specific functions. The table reports odds ratios. Ratios of exactly 1.00 for years 1996 or 1999 would indicate that the chances of reporting the limitation relative to not reporting the limitation are the same in comparison to 1993. Statistically significant ratios greater than 1.00 indicate higher chances of reporting the limitation for the year in question in comparison to 1993, while statistically significant ratios less than 1.00 indicate lower chances.

Looking across these models, it is apparent that, even after taking age, sex, education, ethnicity, and marital status into consideration, older adults in Taiwan were more likely to report limitations in 1996 than in 1993 and in 1999 than in 1993. This is the

Table 4 Odds ratios for functional limitations across survey years

\begin{tabular}{|c|c|c|c|c|c|}
\hline & $\begin{array}{c}\text { Has } \\
\text { difficulty } \\
\text { climbing }\end{array}$ & $\begin{array}{c}\text { Has } \\
\text { difficulty } \\
\text { walking }\end{array}$ & $\begin{array}{l}\text { Has at } \\
\text { least one } \\
\text { limitation }\end{array}$ & $\begin{array}{c}\text { Has both } \\
\text { limitations }\end{array}$ & $\begin{array}{l}\text { Has severe } \\
\text { form of both } \\
\text { limitations }\end{array}$ \\
\hline \multicolumn{6}{|l|}{ Year } \\
\hline 1993 & 1.00 & 1.00 & 1.00 & 1.00 & 1.00 \\
\hline 1996 & $1.33^{* *}$ & $1.15^{*}$ & $1.31^{* *}$ & $1.18^{*}$ & $1.24^{*}$ \\
\hline 1999 & $1.67^{* *}$ & $1.82^{* *}$ & $1.65^{* *}$ & $1.90^{* *}$ & $1.75^{* *}$ \\
\hline \multicolumn{6}{|l|}{ Age } \\
\hline 65 to 69 & 1.00 & 1.00 & 1.00 & 1.00 & 1.00 \\
\hline 70 to 74 & $1.35^{* *}$ & $1.40^{* *}$ & $1.40^{* *}$ & $1.34^{* *}$ & $1.39^{* *}$ \\
\hline 75 to 79 & $2.02^{* *}$ & $2.13^{* *}$ & $2.08^{* *}$ & $2.10^{* *}$ & $2.25^{* *}$ \\
\hline 80 and older & $3.65^{* *}$ & $4.12^{* *}$ & $3.92^{* *}$ & $3.99^{* *}$ & $4.52^{* *}$ \\
\hline \multicolumn{6}{|l|}{ Sex } \\
\hline Male & 1.00 & 1.00 & 1.00 & 1.00 & 1.00 \\
\hline Female & $1.75^{* *}$ & $1.47^{* *}$ & $1.78^{* *}$ & $1.45^{* *}$ & $1.20^{*}$ \\
\hline \multicolumn{6}{|l|}{ Education } \\
\hline None & 1.00 & 1.00 & 1.00 & 1.00 & 1.00 \\
\hline Primary & $0.71^{* *}$ & $0.73^{* *}$ & $0.71^{* *}$ & $0.72^{* *}$ & $0.66^{* *}$ \\
\hline More than primary & $0.41^{* *}$ & $0.43^{* *}$ & $0.39^{* *}$ & $0.44^{* *}$ & $0.40^{* *}$ \\
\hline \multicolumn{6}{|l|}{ Ethnicity } \\
\hline Other & 1.00 & 1.00 & 1.00 & 1.00 & 1.00 \\
\hline Mainlander & $0.84^{* *}$ & $0.73^{* *}$ & $0.79^{* *}$ & $0.78^{* *}$ & $0.65^{* *}$ \\
\hline \multicolumn{6}{|l|}{ Married } \\
\hline No & 1.00 & 1.00 & 1.00 & 1.00 & 1.00 \\
\hline Yes & 1.02 & $0.88^{*}$ & 0.98 & 0.91 & 0.87 \\
\hline LL & -5158.94 & -4461.95 & -5301.59 & -4173.59 & -2845.00 \\
\hline$\Delta-2 \mathrm{LL}$ (Model) & $883.89^{* *}$ & $821.53^{* *}$ & $977.68^{* *}$ & $746.24^{* *}$ & $545.93^{* *}$ \\
\hline
\end{tabular}


case regardless of how limitations are measured. The higher odds ratios in 1999 in comparison to 1996 also indicate a monotonic increase in the chances of reporting at least one limitation across survey years. For example, an odds ratio of 1.31 with respect to the chances of reporting limitation in 1996 means there was about a 31 percent increase in the odds of reporting at least one limitation in 1996 in comparison to 1993, whereas the 1.65 figure for 1999 indicates that the odds ratio further increased over the next three years. All changes in limitation reporting across years are statistically significant.

Age, sex, education, and ethnicity also display strong relationships in the expected directions. The five-year age group variables show increasing probabilities of reporting limitations with rising age. Females are more likely than males to report having limitations. Elderly adults with primary education and those with more than primary education are less likely than those without education to report limitations. Mainlanders are less likely to report limitations than are others. Although those who are married are generally less likely to report limitations, the odds ratios are not statistically significant with the exception of the model for having difficulty walking.

\section{Changes in Survival Probabilities}

The results presented above strongly indicate that older Taiwanese were more likely to report functional limitations, and more likely to report severe limitations, at the end of the 1990s than in the early part of the decade. It is beyond the scope of the current paper to conduct a full examination of the possible explanations for this increased prevalence. Table 5, however, reports inter-survey survival probabilities that may reflect one possible reason - that changes in old-age mortality might have something to do with the increasing prevalence of functional limitation in Taiwan. The first two columns in Table 5 indicate the probability that an individual survived the three-year period between survey waves; this probability is recorded across categories of functional limitations reported at the start of the period. Displayed are probabilities by specific functional limitations and by numbers of limitations and severe limitations. These results are unadjusted for compositional variables; adjustments would require a more focused analysis with greater concentration on the specific issue of mortality changes across time. 
Table 5 Three-year inter-survey survival probabilities by functional status at start of period

\begin{tabular}{|c|c|c|c|c|}
\hline & $\begin{array}{c}\text { Survival } \\
\text { probability } \\
\text { from } \\
1993 \text { to } 1996\end{array}$ & $\begin{array}{c}\text { Survival } \\
\text { probability } \\
\text { from } \\
1996 \text { to } 1999\end{array}$ & $\begin{array}{l}\text { Percent change in } \\
\text { survival probability } \\
\text { between first and } \\
\text { second interval }\end{array}$ & P-value \\
\hline Total & 0.860 & 0.870 & 1.16 & 0.256 \\
\hline \multicolumn{5}{|c|}{ By limitation at start of period } \\
\hline \multicolumn{5}{|c|}{ Difficulty climbing } \\
\hline None & 0.909 & 0.908 & -0.11 & 0.908 \\
\hline Not severe & 0.841 & 0.861 & 2.38 & 0.444 \\
\hline Severe & 0.612 & 0.688 & 12.42 & 0.028 \\
\hline \multicolumn{5}{|c|}{ Difficulty walking } \\
\hline None & 0.908 & 0.901 & -0.77 & 0.403 \\
\hline Not severe & 0.793 & 0.837 & 5.55 & 0.230 \\
\hline Severe & 0.575 & 0.672 & 16.87 & 0.013 \\
\hline \multicolumn{5}{|c|}{ Number of limitations } \\
\hline None & 0.901 & 0.911 & 1.11 & 0.259 \\
\hline One & 0.861 & 0.834 & -3.14 & 0.313 \\
\hline Both & 0.641 & 0.726 & 13.26 & 0.005 \\
\hline \multicolumn{5}{|c|}{ Number of severe limitations } \\
\hline None & 0.894 & 0.904 & 1.12 & 0.235 \\
\hline One & 0.774 & 0.769 & -0.65 & 0.910 \\
\hline Both & 0.532 & 0.648 & 21.80 & 0.008 \\
\hline
\end{tabular}

The first row of the table shows that the probability of surviving from 1993 to 1996 was 0.860 for the total population. This probability increased to 0.870 for the period 1996 to 1999. The third column converts this change to a percent. The chance of surviving the second period was a little over 1 percent greater than the chance of surviving the first period. This represents only a slight decrease in overall mortality, and one that is not statistically significant based on the P-value of the t-test reported in the final column.

Although the total improvement in the chances of surviving was minimal, the remainder of the table shows that, depending on the category of limitation, in a few cases there were substantial changes in survival probability. For instance, the probability rose about 12 percent among those with severe difficulty climbing and 17 percent 
among those with severe difficulty walking. In contrast, there was not a statistically significant change in survival probability for those with no or nonsevere limitations in these functions. The patterns for the summary measures are similar, with the most severely limited experiencing the greatest increases in survival. For those severely limited in both functions, there was a statistically significant 22 percent increase in survival probability.

\section{CONCLUSION}

In contrast to the experience in the United States in the 1980s and 1990s, the physical functioning of older Taiwanese on average deteriorated from 1993 to 1999. The proportions of Taiwanese aged 65 and older reporting walking or climbing limitations and the proportions reporting severe limitations increased even after controlling for changes in population composition in multivariate models. Increases also occurred in the probabilities of these limitations affecting specific age and education groups, as shown bivariately. The increases in limitations are so large that it is unlikely that such a pattern of change could be sustained for long. That is, extrapolating such rates of increase into the future would result in implausibly high prevalence within a short time; therefore, the experience of 1993 to 1999 is certainly unusual.

Comparing levels of functional limitations between Taiwan and the United States is difficult because of differences in questionnaire wording, survey techniques, and the ways in which individuals interpret health in different cultures. But our findings allow us to assert that the pattern of change in Taiwan runs contrary to the improvements in functioning observed in the United States. This divergence may be surprising given that Taiwan has been experiencing rapid socioeconomic development. We can only speculate on the reasons behind this apparent increase in functional limitation among older adults in Taiwan.

Owing to the consistency in survey design and administration across the waves that we use here, we do not believe that the increase is due to changes in the survey. We were particularly careful in choosing two functional tasks for which questions were asked identically across survey waves. Of course, there are challenges associated with 
using a survey primarily designed for longitudinal purposes to analyze changes over time of representative cross-sections of the population. We have attempted to adjust for attrition through imputation. Even if there is some residual loss-to-follow-up for which we are not accounting, it is not likely that the inclusion of these additional cases would significantly improve the overall functional status of the population. In analysis of changes in the health of the U.S. older population, concern is often expressed about the influence of changes in institutionalization over time. But the data set we use includes institutionalized persons in all waves.

One possible explanation for the rise in functional limitations is that there has been increased survival of the elderly with limitations. Survival probabilities showed that although old-age mortality declined in Taiwan, those with more limitations and those with more severe limitations benefited the most from increased survival. In 1995 Taiwan initiated a Universal Health Insurance program that in theory provides older adults with easier and more frequent access to the medical system. Chiang (1997) and Cheng and Chiang (1997) show that over the first year of the program, use of the formal health care sector increased for the previously uninsured. Health insurance programs such as the one established in Taiwan tend to focus on treatment of existing conditions rather than on prevention (Longino 2000). Thus, those who increase their use after initiation may be those most in need of treatment. For this and other reasons, the survival of the elderly with the most severe limitations may have been particularly enhanced by the increase in use of health care.

The introduction of the health insurance program may also have had an effect on how older Taiwanese perceive their health, which in turn could influence the reporting of functional limitations. Besides providing treatment, the new insurance program may have raised expectations about health and thus contributed to an increased perception of functional limitations at a lower level of difficulty. No doubt the information revolution has also increased awareness of health issues. This possibility is consistent with assessments by Riley (1990) and Waidmann, Bound, and Schoenbaum (1995) of the role of changes in perceptions of health as one of the factors accounting for the increased reporting of health problems in the United States and elsewhere in the 1970s. Hence, it is 
possible that the increase in limitations associated with walking and climbing is a function of several forces acting together, such as improvements in survival among those who are most impaired and changes in the perception of health brought about by increased information and improvements in access to health care.

The increase in survival among those most functionally limited in some ways invokes the debate on expansion versus compression of morbidity. In his classic paper, "The failures of success," Gruenberg (1977) suggested that improvements in medical technology were resulting in the removal of the lethal sequelae of disease and thus leaving individuals alive but suffering from severe health problems. An alternative scenario posited by Fries (1980) suggested that as life expectancy rose to its theoretical limit, periods of ill health would be compressed into the very late stages of life, resulting in increases in the amount of time being lived in good health. Both Gruenberg and Fries based their scenarios on the experience of the highly developed countries that were already well along in their epidemiological transitions from a dominance of parasitic, infectious diseases to chronic, degenerative diseases. It could be that both authors are correct, but that their scenarios are relevant at different stages of the transition. Early on, those living to old age would likely have had a considerably greater lifetime burden of health challenges (especially infectious diseases) than those who survive to old age after the epidemiological transition has entered its later stages. Besides differences in disease patterns, older people in countries such as Taiwan (in contrast to the United States) will have experienced substantially different living and working environments in early life and on average will have lived in poorer circumstances and without the benefit of the growing body of knowledge regarding good health practices. Thus, it may not be entirely inconsistent that we can discern improvements in functioning in the United States, where life expectancy had already reached 70 years in the early 1960s (United Nations 2001), as opposed to Taiwan, where it did not reach 70 until the mid-1970s (Ministry of the Interior 1976). It is possible that in Taiwan we are witnessing an earlier stage in morbidity and functioning transition.

This study is the first to find a strong indication of increasing prevalence of functional limitation in a non-Western society, and it has done so using data that span a 
relatively short period, that is, between 1993 and 1999. Clearly additional work is needed both in Taiwan and elsewhere, first to confirm that the change we observed is not due to survey design or a short-term idiosyncrasy, and second to understand the multiple ways in which health and perceptions of health and well-being change over the course of the epidemiological transition, over time, and as populations age. As Crimmins (1996) has observed, health is a multifaceted concept and it should come as no surprise if different dimensions of health change in different ways over different periods. Moreover, as in the United States, much remains to be done in Taiwan to understand the causes of the heterogeneity of trends between different demographic and socioeconomic groups. The past will not necessarily predict the future, but to the extent that the relations between causal factors and health outcomes are stable, then information on how those causal factors might change may provide insight into future health transitions at the population level. There is no doubt that elderly Taiwanese 25 years from now will have substantially different characteristics; for example, they will be much better educated and will have had substantially different early-life experiences.

Regardless of the future course in the prevalence of functional limitations, the number of Taiwanese who will be older will increase dramatically over the next 25 years (DGBAS 2000). Thus, unless substantial improvements in functional status take place, the health care and broader support needs of this segment of the population will expand, making greater demands on public and private services. Only persistent and long-term improvements in functional status will be able to offset changes to the population age structure that are already underway.

\section{REFERENCES}

Cheng, Shou-Hsia and Tung-Liang Chiang. 1997. "The effect of universal health insurance on health care utilization in Taiwan: Results from a natural experiment," Journal of the American Medical Association 278(2): 89-93.

Chiang, Tung-Liang. 1997. “Taiwan's 1995 health care reform," Health Policy 39(3): 225-239. 
Colvez, A. and M. Blanchet. 1981. "Disability trends in the United States population 1966-76: Analysis of reported causes," American Journal of Public Health 71(5): 464-471.

Crimmins, Eileen M. 1996. "Mixed trends in population health among older adults," Journal of Gerontology: Social Sciences 51B(5): S223-S225.

Crimmins, Eileen M., Mark D. Hayward, and Yasuhiko Saito. 1994. "Changing mortality and morbidity rates and health status and life expectancy of the older population," Demography 31(1): 159-175.

Crimmins, Eileen M., Yasuhiko Saito, and Sandra L. Reynolds. 1997. "Further evidence on recent trends in the prevalence and incidence of disability among older Americans from two sources: The LSOA and the NHIS," Journal of Gerontology: Social Sciences 52B(2): S59-S71.

DGBAS (Directorate General of Budget, Accounting and Statistics). 2000. Statistical Yearbook of the Republic of China, 2000. Taipei: Executive Yuan of the Republic of China.

Freedman, Vicki A. and Linda G. Martin. 1998. "Understanding trends in functional limitations among older Americans," American Journal of Public Health 88(10): $1457-1462$.

Freedman, Vicki A. and Linda G. Martin. 1999. "The role of education in explaining and forecasting trends in functional limitations among older Americans," Demography 36(4): 461-473.

Freedman, Vicki A. and Linda G. Martin. 2000. "Contribution of chronic conditions to aggregate changes in old-age functioning," American Journal of Public Health 90(11): 1755-1760.

Fries, James F. 1980. "Aging, natural death and the compression of morbidity," New England Journal of Medicine 303(3): 130-135.

Gruenberg, Ernest M. 1977. "The failures of success," Milbank Memorial Fund Quarterly/Health and Society 55(1): 3-24. 
Hermalin, Albert I. 1995. "Aging in Asia: Setting the research foundation,” Asia-Pacific Population Research Reports No. 4. Honolulu, HI: East-West Center.

Longino, C.F., Jr. 2000. "Beyond the body, an emerging medical paradigm," pp. 39-54 in A.M. Warnes, L. Warren, and M. Nolan (eds.), Care Services for Later Life: Transformations and Critiques. London: Jessica Kingsley Publishers.

Manton, Kenneth G., Larry S. Corder, and Eric Stallard. 1993. "Estimates of change in chronic disability and institutional incidence and prevalence rates in the U. S. elderly population from the 1982, 1984, and 1989 National Long Term Care Survey," Journal of Gerontology 48(4): S153-S166.

Manton, Kenneth G., Larry S. Corder, and Eric Stallard. 1997. "Chronic disability trends in elderly United States populations: 1982-1994," Proceedings of the National Academy of Sciences 94(6): 2593-2598.

Manton, Kenneth G. and XiLiang Gu. 2001. "Changes in the prevalence of chronic disability in the United States black and nonblack population above age 65 from 1982 to 1999," Proceedings of the National Academy of Sciences 98(11): 63546359.

Ministry of the Interior. 1976. 1975 Taiwan-Fukien Demographic Fact Book, Republic of China. Taipei.

Ministry of the Interior. 2000. 1999 Taiwan-Fukien Demographic Fact Book, Republic of China. Taipei.

Nagi, Saad Z. 1965. "Some conceptual issues in disability and rehabilitation," pp. 100113 in Marvin B. Sussman (ed.), Sociology and Rehabilitation. Washington, DC: American Sociological Association.

Nagi, Saad Z. 1991. "Disability concepts revisited: Implications for prevention," pp. 309327 in Andrew M. Pope and Alvin R. Tarlov (eds.), Disability in America: Toward a National Agenda for Prevention. Washington, DC: National Academy Press.

Population Reference Bureau. 1990. 1990 World Population Data Sheet. Washington, DC. 
Population Reference Bureau. 2001. 2001 World Population Data Sheet. Washington, DC.

Riley, James C. 1990. "The risk of being sick: Morbidity trends in four countries," Population and Development Review 16(3): 403-432.

Schoeni, Robert F., Vicki A. Freedman, and Robert B. Wallace. 2001. "Persistent, consistent, widespread, and robust? Another look at recent trends in old-age disability," Journal of Gerontology: Social Sciences 56B(4): S206-S218.

Taiwan Department of Health. 1999. "The National Health Insurance program," Chapter 7 in Taiwan Health Information System. Department of Health, Executive Yuan, Republic of China.

Taiwan Provincial Institute of Family Planning. 1989. 1989 Survey of Health and Living Status of the Elderly in Taiwan: Questionnaire and Survey Design. Taichung.

United Nations. 2001. World Population Prospects: The 2000 Revision. New York.

Verbrugge, Lois M. 1984. "Longer life but worsening health? Trends in health and mortality of middle-aged and older persons," Milbank Memorial Fund Quarterly/ Health and Society 62(3): 474-519.

Waidmann, Timothy, John Bound, and Michael Schoenbaum. 1995. "The illusion of failure: Trends in the self-reported health of the U.S. elderly," Milbank Memorial Fund Quarterly 73(2): 253-287. 


\title{
POLICY RESEARCH DIVISION WORKING PAPERS
}

\author{
Recent Back Issues
}

133 Mary Arends-Kuenning and Sajeda Amin, "The effects of schooling incentive programs on household resource allocation in Bangladesh."

134 John Bongaarts and Charles F. Westoff, "The potential role of contraception in reducing abortion."

135 John B. Casterline and Steven W. Sinding, "Unmet need for family planning in developing countries and implications for population policy."

*136 Carol E. Kaufman, Thea de Wet, and Jonathan Stadler, "Adolescent pregnancy and parenthood in South Africa."

*137 Valerie L. Durrant and Zeba A. Sathar, "Greater investments in children through women's empowerment: A key to demographic change in Pakistan?"

138 Sajeda Amin, Alaka Malwade Basu, and Rob Stephenson, "Spatial variation in contraceptive use in Bangladesh: Looking beyond the borders."
139 Geoffrey McNicoll, "Managing population-environment systems: Problems of institutional design."

140 Barbara S. Mensch, Barbara L. Ibrahim, Susan M. Lee, and Omaima ElGibaly, "Socialization to gender roles and marriage among Egyptian adolescents."

141 John Bongaarts and Elof Johansson, "Future trends in contraception in the developing world: Prevalence and method mix."

142 Alaka Malwade Basu and Sajeda Amin, "Some preconditions for fertility decline in Bengal: History, language identity, and an openness to innovations."

143 Zeba Sathar, Cynthia B. Lloyd, Cem Mete, and Minhaj ul Haque, "Schooling opportunities for girls as a stimulus for fertility change in rural $\mathrm{Pa}-$ kistan." 
144 John Bongaarts, "Household size and composition in the developing world."

145 John B. Casterline, Zeba A. Sathar, and Minhaj ul Haque, "Obstacles to contraceptive use in Pakistan: A study in Punjab."

146 Zachary Zimmer, Albert I. Hermalin, and Hui-Sheng Lin, "Whose education counts? The impact of grown children's education on the physical functioning of their parents in Taiwan."

147 Philomena Nyarko, Brian Pence, and Cornelius Debpuur, "Immunization status and child survival in rural Ghana."

148 John Bongaarts and Zachary Zimmer, "Living arrangements of older adults in the developing world: An analysis of DHS household surveys."

149 Markos Ezra, "Ecological degradation, rural poverty, and migration in Ethiopia: A contextual analysis."
150 Cynthia B. Lloyd, Sahar El Tawila, Wesley H. Clark, and Barbara S. Mensch, "Determinants of educational attainment among adolescents in Egypt: Does school quality make a difference?"

151 Barbara S. Mensch, Paul C. Hewett, and Annabel Erulkar, " The reporting of sensitive behavior among adolescents: A methodological experiment in Kenya."

152 John Bongaarts, "The end of the fertility transition in the developed world."

153 Mark R. Montgomery, GebreEgziabher Kiros, Dominic Agyeman, John B. Casterline, Peter Aglobitse, and Paul C. Hewett, "Social networks and contraceptive dynamics in southern Ghana."

154 Paul C. Hewett and Mark R. Montgomery, "Poverty and public services in developing-country cities."

155 Zachary Zimmer, Linda G. Martin, and Ming-Cheng Chang, "Changes in functional limitations and survival among the elderly in Taiwan: 1993, 1996, and 1999." 